\title{
Limb salvage treatment of large multicentric extra- abdominal desmoid tumor of lower extremity
}

\begin{abstract}
This article presents a case report of large isolated extra-abdominal desmoid tumor on ipsilateral knee and ankle joint, which was successful treated with combination of surgicallimb salvage procedure and oncologist therapy in the form of hormone and anti-infammatory therapy. A 36 years old male comes, five years after primary treatment of tumor mass of the anterior abdominal wall to Department of Orthopedic surgery because he has new two large tumor changes in the front of the right knee (approximate dimensions $26 \times 10 \times 22 \mathrm{~cm}$ (CCxLLxAP)) and ankle joint (16 x 5cm (APxLL)), which have been progressively increased over the time. The optimal management of desmoid tumor has not be established, because this tumor entity is rare and all recommendations for treatment come from the individual cases described in the literature. Combination of surgery, postoperative hormone and anti-inflammatory therapy is best way of treatment for non resectable tumors.
\end{abstract}

Keywords: desmoid tumor, surgery, knee, ankle joint, hormone therapy, anti-inflammatory therapy
Volume 8 Issue 6 - 2017

\author{
Nemanja M Gvozdenović,, 2 Vesna Pajtić1,3 \\ 'Faculty of Medicine, University of Novi Sad, Serbia \\ ${ }^{2}$ Clinic for Orthopaedic Surgery and Traumatology, Clinica \\ Center of Vojvodina, Serbia \\ ${ }^{3}$ Emergency Center, Department of Anesthesia, Clinical Center \\ of Vojvodina, Serbia
}

Correspondence: Vesna Pajtić, Emergency Center, Department of Anesthesia, Clinical Centar of Vojvodina, Hajduk Veljkova I-7, 21000 Novi Sad, Serbia,Tel +38I-63559365, Email vesna.pajtic@mf.uns.ac.rs

Received: May 14, 2017 | Published: October 24, 2017
Abbreviations: DT, desmoid tumor; CT, computerized tomography; MRI, magnetic resonance; RT, radiotherapy

\section{Introduction}

Aggressive fibromatoses or desmoid tumor (DT) is a very rare soft tissue neoplasms with incidence $2-4$ cases per billion every year. ${ }^{1}$ Fibromatoses is fibroblast origin-benign tumor lesion, locally invasive but never metastatic and with high recurrence rate. ${ }^{2}$ There are two types of DT- superficial and the deep group. The deep group is divided into extra abdominal, intra-abdominal and abdominal type and all of them are histologically similar. ${ }^{1}$ Extra abdominal presentation is the rarest type and usually tumor is located on head and neck, ${ }^{3}$ chest wall ${ }^{4}$ and spinal cord. ${ }^{5}$ Limb localization is most often found in the upper extremity - shoulder and arm region, and in lower extremity - buttocks, back of the thigh and knee joint. ${ }^{6-8}$ So far, the literature describes only several cases of anterior lower limb presentation of desmoid tumor, one case presentation in bilateral lower limbs and there are no literature findings of ipsilateral knee and ankle joint presentation (Table 1). ${ }^{7-10}$

Table I Case reports in literature of the lower limb presentation of the extra abdominal desmoid tumor

\begin{tabular}{|c|c|c|c|c|c|c|c|}
\hline $\begin{array}{l}\text { Author/Journal/ } \\
\text { Published }\end{array}$ & Gender & Age & Localization & Histology & Operation & Adjuvant Therapy & $\begin{array}{l}\text { Recurrence or } \\
\text { New Tumor } \\
\text { Growth/Time }\end{array}$ \\
\hline $\begin{array}{l}\text { Shimoyama T, et al. Rare } \\
\text { Tumors } 2010\end{array}$ & $\mathrm{~F}$ & 64 & $\begin{array}{l}\text { bouth legs (posterior } \\
\text { parts of thighs and } \\
\text { popliteal fossa) }\end{array}$ & EADT & LS & Yes (RT) & $\begin{array}{l}\text { Yes } \\
\text { I year }\end{array}$ \\
\hline $\begin{array}{l}\text { Cao C, et al. Oncology } \\
\text { Letters } 2012\end{array}$ & $\mathrm{~F}$ & 52 & lower leg & EADT & TS & No & $\begin{array}{l}\text { Yes } \\
3 \text { months }\end{array}$ \\
\hline $\begin{array}{l}\text { Ling W, et al. BMC } \\
\text { Musculoskelet Disord. } 2013\end{array}$ & M & 49 & $\begin{array}{l}\text { popliteal fossa (posterior } \\
\text { cruciate ligament) }\end{array}$ & EADT & TS & $\begin{array}{l}\text { Yes (low } \\
\text { temperature radio } \\
\text { frequency ablation) }\end{array}$ & No \\
\hline $\begin{array}{l}\text { Arupam T, et al. Indian J } \\
\text { Surg } 2010\end{array}$ & M & 68 & thigh & EADT & TS & No & No \\
\hline $\begin{array}{l}\text { Skapek SX, et al. Pediatr } \\
\text { Blood Cancer. } 2013 \text { (I997- } \\
2009 \text { examination time) }\end{array}$ & No data & $<18$ & $\begin{array}{l}\text { (the back of the thigh } \\
\text { and knee region and the } \\
\text { lower leg) }\end{array}$ & EADT & LS & $\begin{array}{l}\text { Yes (hormone and } \\
\text { anti-inflammatory } \\
\text { therapy) }\end{array}$ & $\begin{array}{l}\text { Yes } \\
(60 \% \text { in } 4 \text { year } \\
\text { period })\end{array}$ \\
\hline $\begin{array}{l}\text { Colterjohn NR, et al. } \\
\text { Sarcoma } 1997\end{array}$ & $\begin{array}{l}M(4) \\
F(2)\end{array}$ & $\approx 51$ & $\begin{array}{l}6 \text { cases on the foot and } \\
\text { ancle }\end{array}$ & EADT & LS & Yes (RT) & $\begin{array}{l}\text { Yes } \\
\text { (100\% in 24- } 109 \\
\text { moths period) }\end{array}$ \\
\hline
\end{tabular}

LS, limb salvage, Partial Surgically Removed, EADT, extra abdominal desmoid tumor; RT, radiotherapy (postoperative); TS, total excision of the tumor; F, female; M, male

Patients with DT usually are young females between $15-35$ years. ${ }^{11}$ Genetical predisposing plays an important role in development od DT, and is often associated with the familial adenomatous polyposis and Gradner's syndrome. Other factors that influence formation of DT are chronic mechanical irritation and surgery induced scars and implants. ${ }^{4,12,13}$ Optimal management for DT has not be established, although surgery with radical resection with wide margins of the tumor remain the primary method of treatment. If surgery is contraindicated or not possible, alternatives are in the form of radiotherapy (RT), ${ }^{14}$ chemotherapy, ${ }^{15}$ hormone and anti-inflammatory therapy ${ }^{16}$ may be 
administered alone or as adjuvant surgical therapy. Because of the rarity of DT, high level evidence of healing does not exist. This article presents a case of large isolated extra- abdominal DT in middle aged male, localized on ipsilateral knee and ankle joint, which was successfully treated by a combination of surgical-limb salvage procedure, postoperative hormone and anti-inflammatory therapy with good final functional result without new tumor growth two years later.

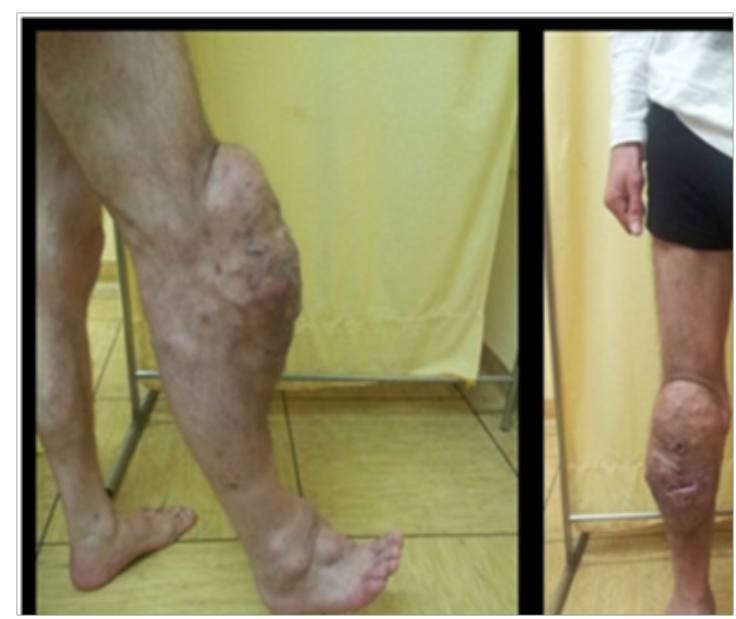

Figure I A large extra-abdominal desmoid tumor of the front of the knee and ankle joint.

\section{Case report}

A 36 years old male came to Department for Orthopedic surgery for examination, because of big tumor of right knee (Figure 1) and ipsilateral ankle joint (Figure 2). These changes had been present for a few years. The first operation was done ten years earlier, when isolated anterior abdominal wall tumor was removed, along with urachus and right $\mathrm{m}$. rectus abdominis, with abdomen wall plastic. Results of pathohistological analysis showed that it was Fibromatosis - Desmoid type - extra abdominal subtype. Five years after primary treatment of tumor mass of the anterior abdominal wall, patient observed new similar changes in the right knee and the ankle joint, which had been progressively increasing over the time. Clinical examination showed a large, foul smelling, tumor mass with ulcerations in anterior region of the knee (Figure 3 ) and tumor changes in the area of the ankle joint.

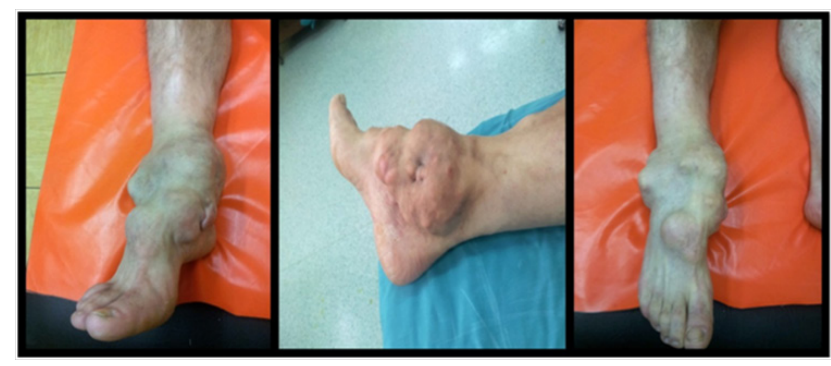

Figure 2 Tumor in the area of the right ankle joint.

Wound was immediately irrigated and debrided. Cottons swabs were taken for bacteriological. Full laboratory analysis and knee and ankle joint $X$ rays were taken. The results show the existence of a local infection caused by Staphylococcus aureus, but without bone involvement. Antibiotics were given and computerized tomography (CT) and magnetic resonance (MRI) was performed. CT and MRI uncovered the presence of fusiform expansive multicentric changes in the region of thigh, knee and lower leg (Figure 4) approximate dimensions $26 \times 10 \times 22 \mathrm{~cm}(\mathrm{CC} \times \mathrm{x}$ LL AP) and in the region of the ankle joint (Figure 5) $16 \times 5 \mathrm{~cm}$ (AP x LL). Tumor changes had characteristics of desmoid tumor, which was confirmed by repeated histological analysis (Figure 6). Limb salvage procedure was done, tumefaction in the right knee and ankle were partial surgically removed. Because tumor had multicentric localization with osseous involvement, any attempt of complete removal of the tumor led to the amputation of the leg. During operation, full passive range of motion of the knee and ankle joint were confirmed. Big resection of soft tissue resulted in large skin defect, which was without any possibility of primary closure. Wound was closed using local skin grafts in cooperation with plastic surgeons. Postoperative adjuvant hormone and anti-inflammatory therapy, recommended by oncologist (Tamoxifen 120mg and Sulindac with doses of $3 \mathrm{mg} / \mathrm{kg}$ daily, one year postoperatively), was immediately started. Follow up controls were uneventful, wound healed completely. Two years later patient had full knee and ankle range of motion without any new tumor growth (Figure 7).

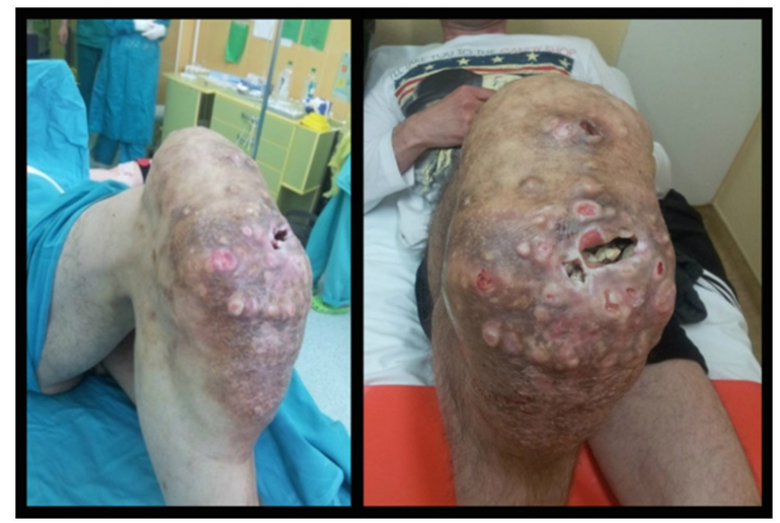

Figure 3 Large local exulceration tumor mass in the area of the front of the knee.

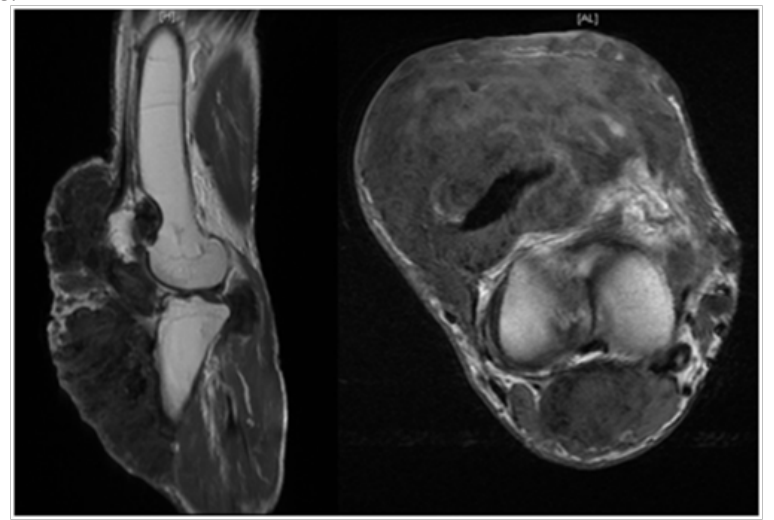

Figure 4 Saggital and axial MRI presence of fusiform expansive multicentric intramuscular changes in the region of thigh, knee and lower leg with infiltration of the bones.

\section{Discussion}

Aggressive fibromatoses or DT is fibroblast origin-benign tumor lesion, locally invasive with high rate of recurrence after treatment, but does not metastasize. ${ }^{2}$ Patients with DT usually are young females between 15-35 years. ${ }^{11}$ Our patient was 36 year old male, and he was younger, compared to patients described in publications with similar localization (lower limbs) of this tumor type. ${ }^{9,10,12,17,18}$ Cao C et al., ${ }^{9}$ and Shimoyama $\mathrm{T}$ et al., ${ }^{18}$ report on DT of lower legs in the middle age females contrary to our case. ${ }^{9,18}$ There are two types of DT-superficial and the deep group. The deep group is divided into 
extra-abdominal, intra-abdominal and abdominal type and all of them are histological similar. Extra-abdominal presentation is the rarest type and usually tumor is located on head and neck, chest wall, upper arm and spinal cord. ${ }^{3-5}$ Enzinger FM et al., ${ }^{19}$ have observed different frequencies of DT presentation depending on its localization: head and neck 34\%, shoulders and upper arm 32\%, trunk $18 \%$ and thigh $16 \% .{ }^{19}$ So far the literature describes only several cases of anterior lower limb presentation of desmoid tumor, one case presentation of bilateral lower limb involvement and there are no literature findings of ipsilateral knee and ankle joint presentation as we have described here (dominant anterior presentation of knee and ankle joint). ${ }^{7-10}$ Ling et al. described a case report of DT in posterior cruciate ligament of the knee, demonstrating the predominant posterior presentation of the tumor. ${ }^{8}$ Posterior localization of DT in lower limbs was also confirmed from other authors in theirs publications. ${ }^{8-10}$

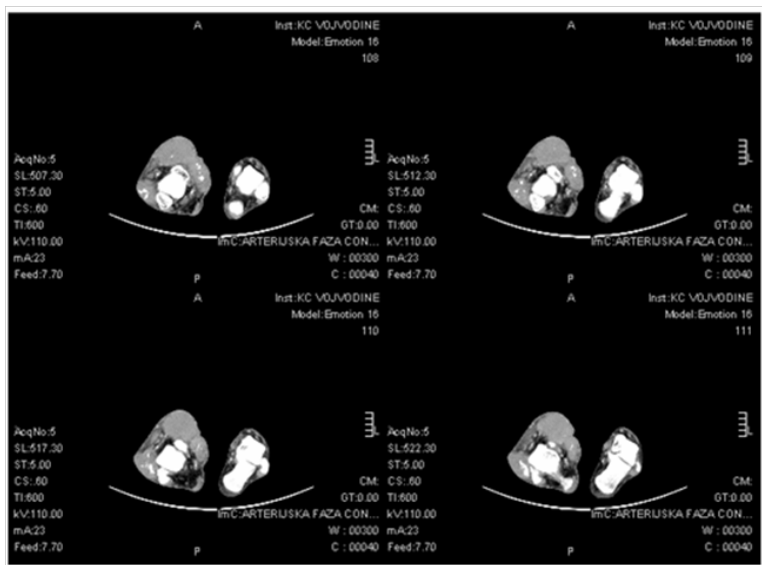

Figure $\mathbf{5}$ Axial CT presences of right ankle joint tumor infiltration.

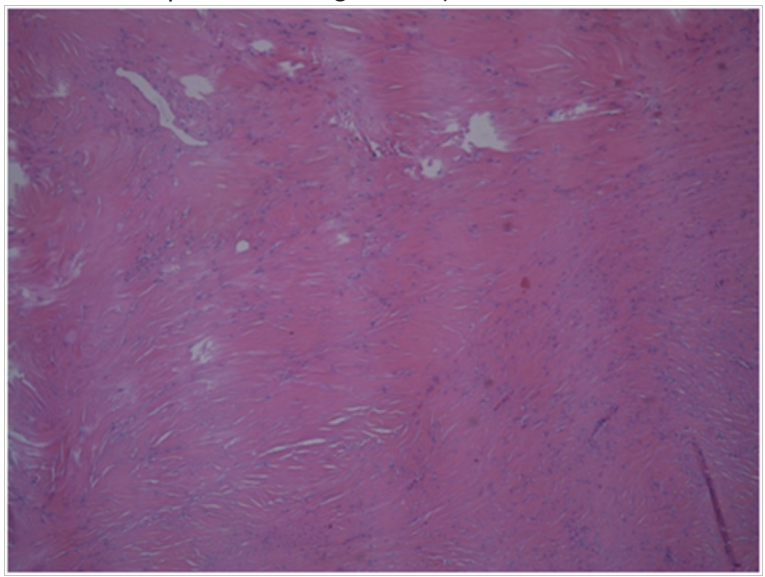

Figure 6 Operative material of the tumor-Histopathological view-well differential elongated, spindle shaped fibroblastic cells separated to one to another by abudant collagen.

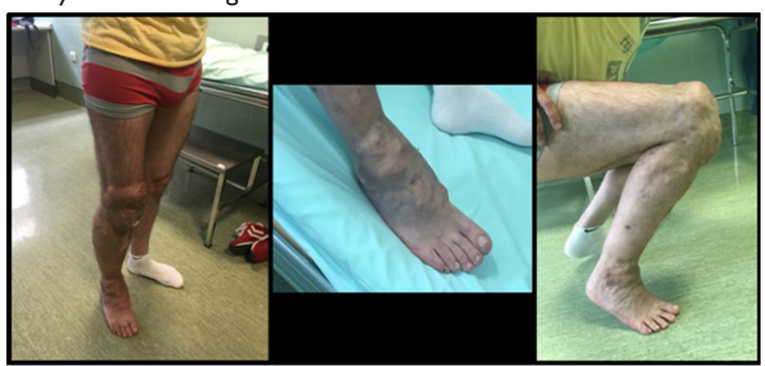

Figure 7 Excellent functional outcome two years after the end of treatment without re-growth of a tumor.
Macroscopically, desmoid tumors are poorly encapsulated and locally invasive, making complete surgical excision difficult and often functionally morbid. Histopathologically the tumor consist of nodular formations with well differential elongated, spindle shaped fibroblastic cells separated by one another with abundant collagen. ${ }^{9}$ Cellular atypia rarely present. Differential diagnosis can be reactive fibrosis or fibroblastic proliferation (scar) and well differentiated fibrosarcomas (cell nuclei are more hyperchromatic and atypical). Some authors reported transformation of extra-abdominal fibromatosis to fibrosarcoma, however there are doubts about the validity of interpretation of bioptic samples, that in fact it was primary fibrosarcoma and not malignant transformation of fibromatosis. ${ }^{20}$ Etiology of DT is not well understood and the lesions are often described as proliferative fibroblastic processes, rather than as true neoplasms. Some authors argue that genetically predisposition is the most important factor for tumor growth, often associated with the familial adenomatous polyposis and Gradner's syndrome, while other authors emphasize the role of environmental factors such as longterm mechanical irritation and inducted surgery scars and implants in formation of DT. ${ }^{4,12,13}$

At the beginning of the treatment it is necessary to obtain the time of occurrence of the tumor (to determine the growth rate), clinical examination as well as radiologic analysis, CT or MRI or both as was in our case, to evaluate the exact position of tumor and structures that are invaded by it. In our case, MRI was showed multicentric localization of the tumor with osseous involvement, which is not typical for this type of tumor. Osseous invasion by DT was described only in few cases in literature, and by Oweis Y et al., ${ }^{21}$ was described bone involvement in extra abdominal, upper limb DT (shoulder presentation) [21]. MRI is the most important modality for tumor detection, preoperative planning and follow-up, but it must be noted that the definitive diagnosis of tumor was set only by histopathologic findings. ${ }^{2,6,13}$ This diagnostic algorithm was applied in our case, with pathohistological confirmation of DT.

The optimal management of DT has not been established, because this tumor entity is rare and all recommendations for the diagnosis and treatment come from the individual cases described in the literature. After setting up the diagnosis, treatment should be individualized and dictated by a multidisciplinary approach, including the surgeon, oncologist, radiologist and histopathologist. The lowest rate of recurrence was after surgical treatment with wide resection of tumor margins. If histopathological findings observe tumor infiltration in resected margins, increased rate of recurrence is expected.,11 Sometimes surgical wide resection is not possible (as was in our case), because of difficult anatomic localization and often functionally unacceptable results. ${ }^{3}$ In order to avoid a high degree of disability that comes with high-femoral amputation or hip disarticulation, we decided to do partial removal of the tumor or limb salvage surgery. The same treatment view was applied by Colterjohn NR et al., ${ }^{10}$ as they showed good functional outcome after limb salvage surgery of 6 cases of foot and ankle fibromatoses. ${ }^{10}$ As an alternative in treatment of unresectable tumors, RT, ${ }^{14}$ chemotherapy, ${ }^{15}$ hormone and anti-inflammatory therapy ${ }^{16}$ can be used as primary therapy or adjuvant therapy after partial surgical resection. Merchant $\mathrm{N}$ et al., ${ }^{22}$ in his study reported lower rate of recurrence of tumor after surgical resection and adjuvant radiotherapy. ${ }^{22}$ As opposed to Merchant N., a large number of authors concluded that RT had no effect on tumor growth and potential only can be used secondary after hormone and anti-inflammatory therapy in unresectable tumors. ${ }^{3,14,23}$ Colterjohn NR et al., ${ }^{10}$ (case report) had $100 \%$ and Skapek SX et al., ${ }^{24}$ (7 cases) had $60 \%$ of recurrence rate after postoperative radiotherapy. ${ }^{10,24}$ 
Clinical studies showed a potential role of female sex hormone estrogen in the development of DT. ${ }^{16,24}$ In our case, presence of estrogen receptors in tumor tissue was confirmed by antibody immunohistochemistry staining. Estrogen receptor blockers (Tamoxsifen) were used in the treatment of DT alone or in combination with anti-inflammatory drugs. ${ }^{16,24}$ Hansman A et al..${ }^{24}$ noted slowdown or discontinuation of growth of DT using combination of hormone (Tamoxsifen 120mg) and anti-inflammatory therapy (Sulindac $300 \mathrm{mg}$ ) daily for 6 months. ${ }^{16}$ Skapek S et al. ${ }^{16}$ concluded that optimal treatment period of DT with combination of Tamoxifen $(120 \mathrm{mg})$ and Sulidac $(3 \mathrm{mg} / \mathrm{kg})$ was one year. ${ }^{24}$ Glucocorticosteroid therapy or non-steroidal anti-inflammatory drugs (NSAIL) usually were used to treat pain and inflammation. Literature findings show NSAIL as an anticancer drug, with good results in treatment of recurrent desmoid tumors. ${ }^{16,25,26}$ In our patient we used similar combination of drugs postoperatively, in duration of one year, and had not observed any toxic effect. Chemotherapy (Cytostatic therapy) represents the last treatment possibility. This type of therapy has bigger role in treatment of intra-abdominal type of fibromatoses and desmoids associated with the familial adenomatous polyposis rather than extra abdominal DT presentation as was in our case. ${ }^{15-17,24}$

The recurrence rate of DT according to Teixeira LE et al. is $33 \%$, with $85 \%$ presenting in first 18 months after the end of treatment. ${ }^{11} \mathrm{~A}$ study of 21 patients with DT has shown that gender, age, localization and number of previous recurrences does not affect the recurrence rate of the tumor. ${ }^{11}$ We presented a challenging case of DT in which we supported the notion of surgery as treatment of choice, but with functional preservation of anatomical structures. With this approach, limb salvage surgery with adjuvant postoperative combination of hormone and anti-inflammatory therapy, we managed to obtain good final result, full range of motion in the knee and ankle joint, without recurrence and new tumor growth in two years follow up.

\section{Contributions of authors}

Nemanja M. Gvozdenovic - conceived and designed the experiment, performed the experiment and wrote the paper.

Vesna Pajtić - performed the experiment; analyzed and interpreted the data, contributed reagents, materials, analysis tools or data and translate the manuscript.

All the authors approved the final manuscript.

\section{Acknowledgments}

None.

\section{Conflicts of interest}

No competing interests declared.

\section{References}

1. Reitamo JJ, Scheinin TM, Hayry P. The desmoid sydrome. New aspects in the cause, patogenesis and traetment of the desmoid tumor. Am J Surg. $1986 ; 151(2): 230-237$

2. World Health Organisation Classification of Tumors. In: Flecher CDM, Unni KK, Mertens F, (Eds.), Pathology and genetics tumor of soft tissue and bone. IARC Press: Lyon, France; 2002.

3. Chu KF, Samara MS, Laver N, et al. A rare presentation of large extra-abdominal desmoid tumor of the posterior neck and back. Am J Otolaryngol. 2013;34(6):727-730.

4. Aaron AD, O’Mara JW, Legendre KE, et al. Chest wall fibromatosis associated with silicone brest implants. Surg Oncol. 1996;5(2):93-99.
5. Shakur SF, Takagi I, Jacobsohn JA, et al. Spinal fibromatosis: a report of two cases and review of the literature. Spine J. 2013;13(8):e1-6.

6. Kasper B, Ströbel P, Hohenberger P. Desmoid Tumors: Clinical Features and Treatment Options for Advanced Disease. Oncologist. 2011;16(5):682-693.

7. Tiwari A, Topno M, Karim T, et al. A Rare Case of Desmoid Tumor of Thigh. Indian J Surg. 2010;72(5):409-411.

8. Ling W, Kedong S, Hong W, et al. Desmoid tumor of posterior cruciate ligament of the knee: a case report. BMC Musculoskelet Disord. $2013 ; 14: 69$

9. Shimoyama T, Hiraoka K, Shoda T, et al. Multicentric extra-abdominal desmoid tumors arising in bilateral lower limbs. Rare Tumors. 2010;2(1):12.

10. Colterjohn NR, Davis AM, O'Sullivan B, et al. Functional outcome in limb-salvage surgery for soft tissue tumours of the foot and ankle. Sarcoma. 1997;1(2):67-74.

11. Teixeira LE, Arantes EC, Villela RF, et al. Extra-abdominal desmoid tumor: local recurrence and treatment options. Acta Ortop Bras. 2016;24(3):147-150.

12. Hatzimarkou A, Filippou D, Papadopoulos V, et al. Desmoid tumor in Gardner's Syndrome presented as acute abdomen. World J Surg Oncol. 2006;28:4-18.

13. Montgomery E, Lee JH, Abraham SC, et al. Superficial fibromatoses are genetically distinct from deep fibromatoses. Mod Pathol. 2001;14(7):695-701.

14. Gluck I, Griffith KA, Biermann JS, et al. Role of Radiotherapy in the Management of Desmoid Tumors. Ind J Radiation Oncology Biol Phys. 2011;80(3):787-792.

15. Garbay D, Le Cesne A, Penel N, et al. Chemotherapy in patients with desmoid tumors: a study from the French Sarcoma Group (FSG). Ann Oncol. 2012;23(1):182-186.

16. Hansmann A, Adolph C, Vogel $\mathrm{T}$, et al. High-dose tamoxifen and sulindac as first-line treatment for desmoid tumors. Cancer. 2004;100(3):612-620.

17. Patel SR, Benjamin RS. Desmoid tumors respond to chemotherapy: defying the dogma in oncology. J Clin Oncol. 2006;24(1):11-12.

18. Cao C, Zou J, Wu C, et al. Wide local excision and reconstructive surgery of desmoid tumour of the crus. Oncol Lett. 2012;4(3):435-437.

19. Enzinger FM, Weiss SW. Infantile (desmoid type) fibromatosis. In: Hupp JR (Ed.), Soft Tissue Tumors. $3^{\text {rd }}$ ed. Mosby: St Louis, USA; 1995. 231-268 p.

20. Tolan S, Shanks JH, Loh MY, et al. Fibromatosis: Benign by Name but not Necessarily by Nature. Clin Oncol (R Coll Radiol). 2007;19(5):319-326.

21. Oweis Y, Lucas DR, Brandon CJ, et al. Extra-abdominal desmoid tumor with osseous involvement. Skeletal Radiol. 2012;41(4):483-487.

22. Merchant NB, Lewis JJ, Woodruff JM, et al. Extremity and trunk desmoid tumors: A multifactorial analysis of outcome. Cancer. 1999;86(10):2045-2052.

23. Nuyttens JJ, Rust PF, Thomas CR Jr, et al. Surgery versus radiation therapy for patients with aggressive fibromatosis or desmoid tumors: A comparative review of 22 articles. Cancer. 2000;88(7):1517-1523.

24. Skapek SX, Anderson JR, Hill DA, et al. Safety and Efficacy of HighDose Tamoxifen and Sulindac for Desmoid Tumor in Children: Results of a Children's Oncology Group (COG) Phase II Study. Pediatr Blood Cancer. 2013;60(7):1108-1112.

25. Hilovska L, Jendželovsky R, Fedoročko P. Potency of non-steroidal antiinflammatory drugs in chemotherapy. Mol Clin Oncol. 2015;3(1):3-12.

26. Vučinić V, Stjepanović M, Ivanov J, et al. Nesteroidna terapija sarkoidoze. Med Pregl. 2013;66(1):60-66. 